\title{
The European Baseline Series in Romania: Results of Patch Testing in Contact Dermatitis and Determination of the Most Frequently Awareness in Adult Patients
}

\author{
MARIA-MAGDALENA CONSTANTIN ${ }^{12 *}$, STEFANA BUCUR ${ }^{2}$, CLARA MATEI $^{1}$, IULIANA ELENA NITA ${ }^{2}$, TRAIAN CONSTANTIN ${ }^{1}$ \\ ${ }^{1}$ University of Medicine and Pharmacy Carol Davila, 37 Dionisie Lupu Str., 020021, Bucharest, Romania \\ ${ }^{2}$ Colentina Clinical Hospital, 19-21 Stefan cel Mare Blvd., 020125, Bucharest, Romania
}

\begin{abstract}
In Romania, data on patch testing are lacking and the significance and applicability of the European baseline series (EBS) needs to be evaluated. The aim of the study was to examine the prevalence of contact allergy to the EBS and to determine the most common post-test sensitization occurred in the population of patients with suspected allergic contact dermatitis in Romania. Demographic data were collected from 252 patients with suspected allergic contact dermatitis. Pacients were patch tested with 28-allergen EBS.The positive patch test was observed in $80.16 \%$ patients. The most prevalent contact allergens were nickel sulphate (15.08\%), fragrance mix I \& II (13.10\%) and potassium dichromate (9.52\%). Differences in sensitization prevalences to some allergens of the EBS compared with other European countries were recognized. The current EBS is a suitable diagnostic tool for contact allergy in Romania.
\end{abstract}

Keywords: allergens, European baseline series, contact allergy, patch testing

The prevalence of contactallergy in general population is estimated at 25 - $40 \%$, while the prevalence of allergic contact dermatitis over lifetime is approximately $10 \%$.

Contact dermatitis (eczema) is a cutaneous inflammatory process occurred at the place where direct contact is made with a harmful substance for the body. Allergic contact dermatitis is based on the pathophysiological mechanism of delayed hypersensitivity (type IV reaction), reaction typically exemplified by allergic eczema determined by contact with poison ivy. There are over 4 000 chemicals described that can cause allergic contact dermatitis [1] and information on new ones are published every year. Dermatological disorders among which contact dermatitis holds the first place are responsible for over a half of the occupational diseases [2].

Considered the "father" of contact dermatitis, Jozef Jadassohn (1863-1936) described this condition and released patch testing technique, a technique which is today essential diagnostic method for finding contact allergy. Diagnosis of allergic contact dermatitis involves two main features: the establishment of delayed hypersensitivity and patient exposed demonstration to some sensitization, both processes of this type of condition warranting investigation. In vivo, delayed hypersensitivity can be demonstrated by applying patch testing and in vitro by performing lymphoblastic transformation tests [3].

Patch testing is the best method for diagnosis the contact allergy, this technique being superior over in vitro tests because the advantage of skin testing, the target organ for allergic contact dermatitis. Patients with relevant history of contact dermatitis is re-exposed to a suspected allergen to be the causative, exposure takes place under safety controlled conditions to verify the diagnostic.

Clinical trials [4] demonstrate the beneficial effect of this method on patients and their positively influence on the quality of life $[5,6]$. However, random testing of patients, even with baseline series of tests is not recommended [7] due to the fact that patch test is considered a biological provocation test. In this sense, when we want to perform this bioassay have to pay attention to certain factors relating to test material, test system, functional and biological status of the person tested and not least the competence and experience of the doctors who performed $[3,8]$.

\section{Experimental part}

The epidemiological study we conducted evaluated 252 patients ( 166 women and 86 men) suspected of having allergic contact dermatitis after anamnestic and clinical data. The study was conducted over a period of 4 years and ittargeted patch testing of these patients (appreciation of the utility and efficiency of this diagnosing method for confirming contact hypersensitivity) and the discovery of most frequent sensitivities in Romanian patients.

The patients included in the study were given a thorough anamnesis (history, occupation, exposure, atopy, comorbidities) doubled by an elaborate clinical examination and filling out a questionnaire. Every subject was informed of the testing purpose, the procedure type, the potential side effects and signed a consent, a document with medical-legal value.

The patch test procedure is an epicutaneous diagnostic provocation test using standardized haptens. Patch testing is performed by applying haptens into small chambers mounted on tape and placed onto the patient's skin. Application technique is relatively simple and consists in applying the test substance (allergen) in small amounts of dilution on the intact skin surface of the patient, under bandage occlusion for a determinate period of time ( $48 \mathrm{~h}$ ). To obtain an optimal bioavailability, must take into account the following factors: the molecule's strong allergen applied penetration ability, its concentration and dose, the vehicle in which is transported, the occlusion patch and exposure.

Preferred areas for allergens application are the superoposterior chest (par vertebral and interscapulo-humeral), applying bands by exerting a light pressure, from the bottom up. If the patient has active lesions on the mentioned areas may be considered other areas such as front of forearm, the internal and external arms or external region of the thighs (fig. 1). 


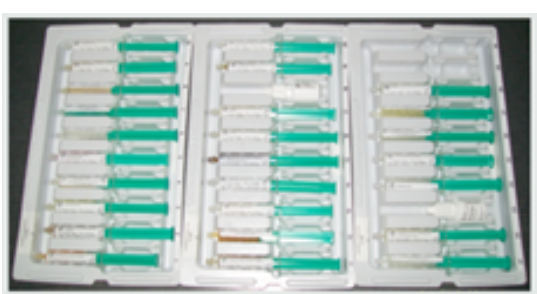

\begin{tabular}{|c|c|c|}
\hline Symbol & Tnterpretation & Morphology \\
\hline $07=$ & Negative reaction & without reaction \\
\hline$?$ & Doübffül reaction & erythema, withoüt infiltration \\
\hline+ & Weak positive reaction & erythema, infiltration, possibly discrete papules \\
\hline++ & Strong positive reaction & erythema, infiltration, papules, vesicles \\
\hline+++ & Extreme positive reaction & erythema, infiltration, papüles, vesicles confluent, bülae \\
\hline $\mathrm{TR}$ & Triritant reaction & $\begin{array}{l}\text { Various types of reactions } \\
\text { (vesicles, bullae, necrosis) }\end{array}$ \\
\hline NT & Not tested & \\
\hline
\end{tabular}

Fig. 1. Allergen application (European baseline series)
The test is maintained $48 \mathrm{~h}$ after that the reading is done, usually 20 min of lifting, then at 24, 48 and even $72 \mathrm{~h}$. Patients undergoing this allergy testing should be informed to avoid activities that result in sweating, irradiation and grooming areas involved. The doctor should also explain local contraindications related testing periods to avoid aggravation of the disease, if generalized rash cortisone topics application and general contraindications such as systemic cortisone treatments, immunosuppressant drugs and NSAIDs. Regarding the per os treatment with antihistamines patch test application, is now considered as having no influence [3].

Reading and evaluation of patch test results are based on morphological criteria, butthe final interpretation should be done in a comprehensive way that includes the patient's medical history, clinical observations and exposure assessment.
Practically, the differentiation of the negative and positive reactions should be tracked and the positive ones must be placed on a quantitative scale. The results of patch-testing can be marked according to the recommendations of ICDRG members [9] (table 1).

Patients were carefully monitored, the reading and the interpretation were noted in an individual tracking file with the subsequent centralized data.

For conducting this study we used European Baseline Series - EBS, recommended by European Environmental and Contact Dermatitis Research Group (EECDRG) which contains the main allergens (28), which have been proven statistically to be the most frequent incriminated to produce an allergic contact dermatitis in this geographic region of the world (table 2). The kit components are dynamic, they are changing constantly depending on epidemiological trends, the appearance or extinction from year to year of specific allergens for different allergic etiologies.

\begin{tabular}{|l|l|}
\hline Allergen (conc. \%) & Vehicle \\
\hline Potassium dichromate & $0,5 \%$ petrolatum \\
\hline Cobalt chloride & $1 \%$ petrolatum \\
\hline Nickel sulfate hexahydrate base & $1 \%$ petrolatum \\
\hline $\begin{array}{l}\text { Paraphenylenediamine free } \\
\text { diaminobenzene }\end{array}$ & $1 \%$ petrolatum \\
\hline Thiuram mix & $20 \%$ petrolatum \\
\hline Neomycin sulfate & $5 \%$ petrolatum \\
\hline Benzocaine & $5 \%$ petrolatum \\
\hline Clioquinol (quinoform) & $0,01 \%$ petrolatum \\
\hline Budesonide & $0,1 \%$ petrolatum \\
\hline Tixocortol pivalate & $20 \%$ petrolatum \\
\hline Colophony & $25 \%$ petrolatum \\
\hline Peru balsam & $0,01 \%$ water \\
\hline Chloro-methyl-isothiazolinone & $16 \%$ petrolatum \\
\hline Paraben mix & $0,1 \%$ petrolatum \\
\hline $\begin{array}{l}\text { N-isopropyl-N-phenylpyraphenylenediamine } \\
\text { (IPPD) }\end{array}$ & $30 \%$ petrolatum \\
\hline Wool Alcohols (Lanolin) & $1 \%$ petrolatum \\
\hline Mercapto mix & \\
\hline Epoxy resins & $5 \%$ petrolum \\
\hline
\end{tabular}




\begin{tabular}{|l|l|}
\hline P-tertiary butylphenol formaldehyde resin & $1 \%$ petrolatum \\
\hline Mercaptobenzothiazole (MBT) & $2 \%$ petrolatum \\
\hline Formaldehyde & $1 \%$ water \\
\hline Perfumes mix I & $8 \%$ petrolatum \\
\hline Sesquiterpene lactones mix & $0,1 \%$ petrolatum \\
\hline Quaternium 15 & $1 \%$ petrolatum \\
\hline Primene & $0,01 \%$ petrolatum \\
\hline Methyl-dibromo-glutaronitrile & $0,5 \%$ petrolatum \\
\hline Perfumes mix II & $14 \%$ petrolatum \\
\hline Hydroxyisohexyl-3-cycohexene carboxaldehyde (Lyral) & $5 \%$ petrolatum \\
\hline
\end{tabular}

Table 2

Continuated
Allergens must be as pure as they can be trom chemical view point [10], deposited in adequate conditions of temperature, humidity, light and standardized, the producing companies taking into consideration the opinion of EECDRG members. Each allergen is placed into a vehicle (white petrolatum/water), the first being the most widespread and favorite due to its good occlusion, allergenic stability and reasonable cost [11]. Liquid vehicles are also used, like some solvents (acetone, ethanol, formaldehyde), but the most modern ones are considered hydrophilic gels (cellulose derivatives). The applying strips of the original system, once made from colophony, were replaced by adhesive ones, based on acrylate or inert additives.

\section{Results and discussions}

The batch analyzed in this study contained a number of 252 patients, out of which 166 women (65.87 \%) and 86 men (34.13\%), a sex ratio of $2: 1$. The selected adult patients were aged between 18 and 70 (the average age $=45.5$ years old). The patients from this batch tested to the 28 allergens from the European battery were positive for the contact allergy in $80.16 \%$. There were also registered irritant reactions in $10.71 \%$ of the patients and $9.13 \%$ were considered negative (tests with doubtful reactions have been taken into account here).
The allergens from the European battery applied to the studied batch has a distribution illustrated in the graphic representation in figure 2, the first 7 allergens in order of frequency are: nickel sulfate (18.81\%), perfumes mix $(15.84 \%)$, potassium dichromate $(11.88 \%)$, Peru balsam $(10.40 \%)$, para-phenylenediamine $(7.92 \%)$, neomycin (6.44\%) and cobalt chloride (5.45\%).

This study followed some relevant aspects of the first three allergens, in the order of frequency of their appearance in the analyzed batch (nickel, perfumes and chromium). Therefore, there were 38 patients sensitive at nickel, $18.81 \%$ of the patients with positive cutaneous reactions and $15.08 \%$ of total subjects. Women, as we expected, were more sensitive $(30-14.85 \%)$ at this metal compared to men ( $8-3.96 \%)$. The most damaged by the nickel exposure were the young adult women (30-39 years old), with a non-professional allergen source (2.48\%). Regarding the professional exposure, 8 patients out of 38 identified it as a possible source (21.05\%), most of them being mature adults ( $50-59$ years old).

The perfumes mix sensitization (fragrance mix I and II) was noted at 33 patients, meaning $16.34 \%$ of the patients with positive cutaneous reactions and $13.10 \%$ of total subjects in the batch. Again, predictable, the female sex

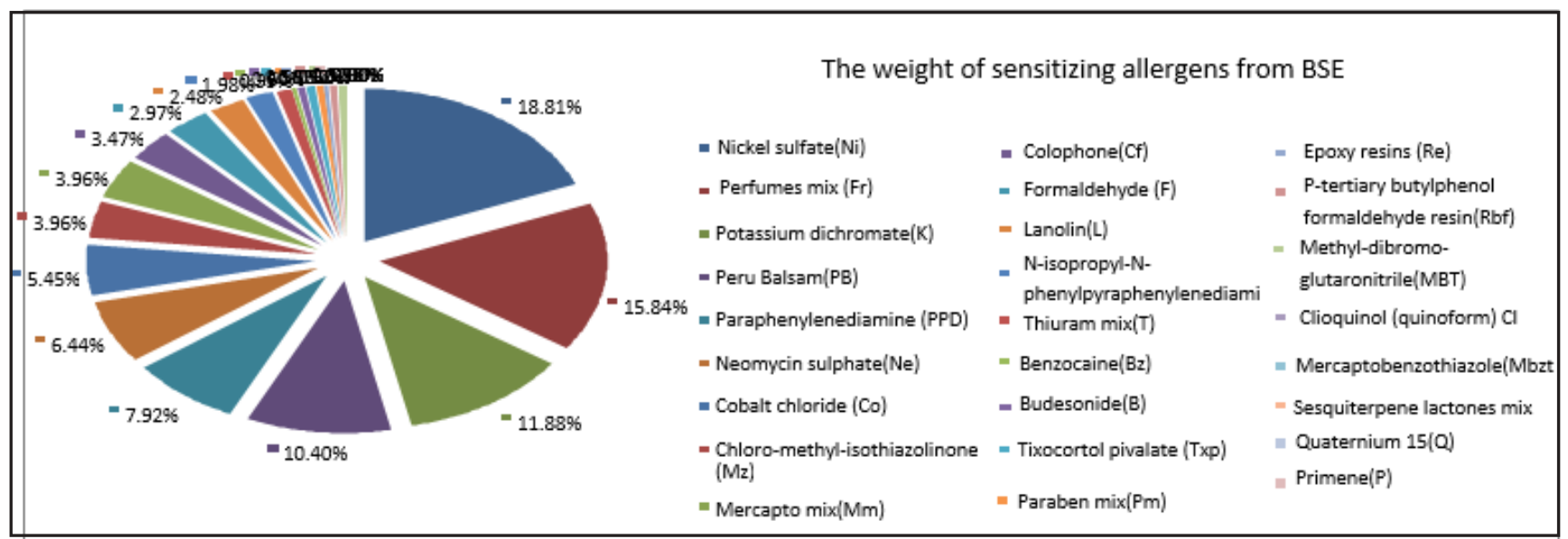

Fig. 2. The weight of sensitizing allergens from EBS

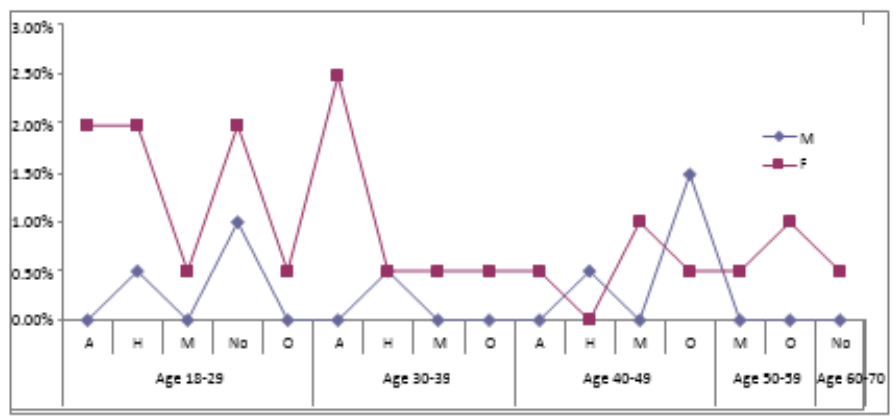

Fig. 3. Ni sensitization rate depending on sex, age and type of activity 
was best represented ( 24 out of 33 patients $-72.73 \%$ ), but the statistical analysis shows that the percentage of perfumes allergies does not differ significantly in women (14.5\%) compared to men (10.5\%) for the entire batch. Also in the perfumes allergy, the age group 30-39 years old was well represented, especially for women exposed to non-professional sources. The exposure to nonoccupational sources was the widest (23 patients out of $33-69.70 \%$ ) in the case of perfumes mix (fig. 4).

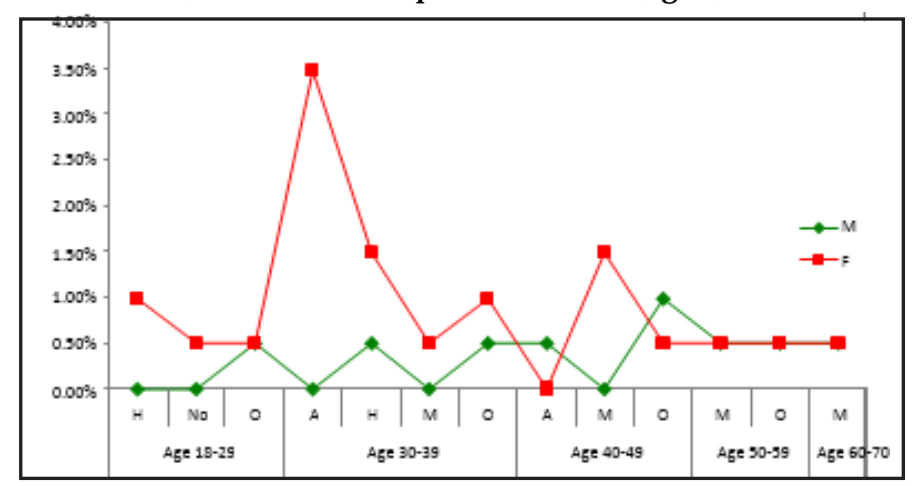

Fig.4. Fr sensitization rate depending on sex, age and type of activity

The prevalence of potassium dichromate allergy, the third allergen in order of frequency in our batch, was 9.52\% and it represented $11.88 \%$ (24 out of 202) out of the total allergic patients. This time, male sex was best represented (18/24- 75\%). The potassium dichromate allergy percentage differs significantly in women (3.6\%) compared to men $(20.9 \%), p=0.000$. The most affected by potassium dichromate exposure were men, age group 40-49 years old, with the allergen from occupational source (19 out of 24 sensitized at $K-71.17 \%$ ), (fig. 5). The positive test percentages at dichromate differ significantly according to the occupational criterion $(p=0.000)$.

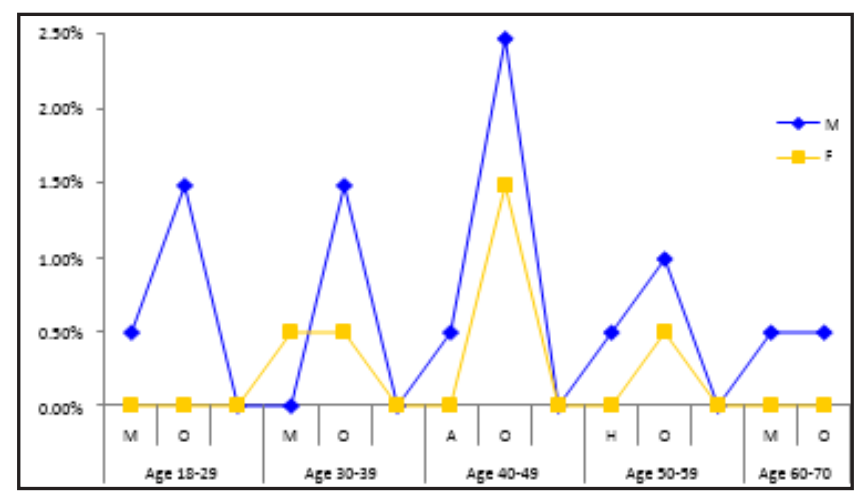

Fig. 5. K sensitization rate depending on sex, age and type of activity

In Europe and in the most parts of the world, the most frequent contact sensitizer is nickel, sensitization to this metal being around $13-17 \%$ for adults $[12,13]$. Women have a much higher risk developing a nickel contactallergy, due to a higher exposure to sources: jewelry, watches straps, metal accessories for clothes, housekeeping, cosmetics, dental alloys [14] etc.

The second allergen in order of frequency in this study was represented by perfumes, perfumes mix sensitization being $13.10 \%$ out of the total subjects in the batch. A German study of the general population indicates a perfumes allergic dermatitis prevalence of $15.90 \%$.

Potassium dichromate, the third allergen in order of frequency identified in our study, had a prevalence of 9.52 $\%$, representing $11.88 \%$ out of the total contact allergies detected through patch-testing. Chromium represents an ubiquitous allergen, especially hexavalent chromium, with mainly occupational sources (construction - cement, leather industry, paints) [15] and affects especially male sex. Numerous studies conducted over time reflect that chromium contact dermatitis prevalence has decreased in the last 25 years [16], but there are reports that indicate that it is quite significant [17-19]. The decrease of the prevalence might be explained through the improvement of working conditions, the developing of prevention and the education of population, the decreasing contact with toxic materials [20], the addition of ferrous sulphate in cement composition [21, 22], the increase of quality of care and housekeeping products etc. [23].

In conclusion, the patch-testing done on 252 patients, mostly of female sex $(65.87 \%)$, showed the presence of positive tests for contact allergy in $80.16 \%$ of cases. The high prevalence of women can be reasoned due to a higher exposure through increased addressability and the presence of a large number of allergens in beauty products, perfumes, clothing, housekeeping products or domestic activities.

\section{Conclusions}

In the last decades, contact sensitization has become a great public health problem [24], the profile of this sensitization being naturally different from country to country. Patch-testing still remains the most efficient diagnostic method of a contact allergy, determining the identification and consecutive avoidance of the trigger allergen, limiting the symptoms, reducing therapy costs and ultimately improving the quality of life of these patients.

The frequencies of sensitization to allergens of the European baselines series, often supplemented by regionspecific contact allergens, are continuously analyzed in most European countries. On the basis of the resulting findings, the composition of the European baseline series is permanently revised and the relevance to allergen exposure is maintained.

\section{References}

1.DE GROOT AC. Patch testing. Test concentration and vehicles for 4320 chemicals, $3 \mathrm{rd}$ edn. Wapserveen. The Netherlands. 2008

2. CONSTANTIN MM. Therapeutics, Pharmacology and Clinical Toxicology. XVI, nr.4, 2012, p.246-249

3. CONSTANTIN MM. Romanian J ournal of Laboratory Medicine. 20, Nr. 3/4, 2012; p.287-292

4. OLTEANU R, ZOTA A, CONSTANTIN MM. Acta Dermatovenerologica Croatica, 25 (1), 2017, p.57-66

5. THOMSON KF, WILKINSON SM, SOMMER S, POLLOCK B. Br. J Dermatol, 146, 2002, p. 627-630

6. WOO PN, HAY IC, ORMEROD AS. Contact Dermatitis., 48, 2003, p.244-247

7. VAN DER VALK PGM, DEVOS SA, COENRAADS P-J. Contact Dermatitis., 48, 2003, p.121-125

8. MOWAD CM. Curr Opin Allergy Clin Immunol., 6, 2006, p.340-344 9. FREGERT S. Manual of Contact Dermatitis. On behalf of the International Contact Dermatitis Research Group and the North American Contact Dermatitis Group. Copenhagen: Munksgaard Publishers.1981/2nd edition

10. RYBERG K, GRUVBERGER B, ZIMERSON E, ISAKSSON M, PERSSON L, SORENSEN $O$ et al. Contact Dermatitis, 58, 2008, p.199-209

11. BRUZE M, ISAKSSON M, GRUVBERGER B, FRICK-ENGFELDT $M$. Contact Dermatitis., 56, 2007, p.281-285

12. DOTTERUD S-S. Contact Dermatitis., 56, 2007, p10-15

13. UTER W, HEGEWALD J, ABERER W et al. Contact Dermatitis., 53, 2005, p.136-145 
14. COVACIU ROMONTI, MILOSEV, I., DEMETRESCU, I., Rev. Chim. (Bucharest), 67, no. 6, 2016, p. 1097-1103

15. GEIER J, LESSMAN H, HELLWEG B et al. Contact Dermatitis., 60, 2009, p.199-202

16. PROCTOR DM, FREDRICK MM, SCOTT PK et al. Regul Toxicol Pharmacol., 28, 1998, p.27-37

17. BALASUBRAMAMIAM P, GAWKRODGER DJ. Contact Dermatitis.,

49, 2003, p.162-163

18. BOCK M, SCHMIDT A, BRUCKNER T et al. Br J Dermatol., 149, 2003, p.1165-1171

19. UTER W, RUHL R, PFAHLBERG A et al. Ann Occup Hyg. 48, 2004 p.21-27
20. ESTLANDER T. Acta Derm Venereol Suppl (Stockh). 155, 1990, p.185.

21. J OHANSEN J, MENNE T, CHRISPHESEN J et al. Br J Dermatol., 142, 2000, p.490-495

22. THYSSEN JP, JENSEN P, KARLSEN BC et al. Br J Dermatol., 161(6), 2009, p.1288-1293.

23. OLTEANU R, CONSTANTIN MM, ZOTA A et al. Farmacia, 64(6), 2016, p.918-921

24. GHEUCA SOLOVASTRU L, VATA D, STATESCU L, CONSTANTIN MM, ANDRESE E. Rev. Rom. Bioet, 12 (2), 2014, p.47-52.

$\overline{\text { Manuscript received: } 5.01 .2018}$ 